\title{
11 \\ Business Model Innovation for Sustainability Through Localism
}

\author{
Linn Meidell Dybdahl『
}

\section{Introduction}

The world is facing social and environmental grand challenges that need to be tackled, and businesses can play an important role in this process as put forward in the introductory chapter of this book. To pursue sustainability or a triple bottom line, companies should integrate environmental and social considerations in their business models. These models are the architecture of how companies create, deliver, and capture value. To create sustainable value or shared value means that the business goal is not just to create profit for the shareholders, but to generate value for a broad range of stakeholders. Shared value is created through 'policies and operating practices that enhance the competitiveness of a company while simultaneously advancing the economic and social conditions in the

L. M. Dybdahl ( $\square)$

Nordic Institute for Studies in Innovation, Research, and Education, Oslo, Norway e-mail: linn.meidell.dybdahl@nifu.no 
communities in which it (...) operates' (Porter and Kramer 2011: 66). It is about combining the self-interest of companies with societal improvements (Lüdeke-Freund et al. 2016).

Companies can explore various strategies or 'design themes' (Zott and Amit 2008) to innovate their business models for sustainability (e.g. Bocken et al. 2014; Clinton and Whisnant 2014). However, there are currently few case studies, which makes it challenging for companies to understand how sustainability-oriented innovation can be done (Evans et al. 2017).

This chapter will explore how pursuing localism can lead to innovation in business models for sustainability in the textile and fashion industry. Localism is defined as a business strategy where companies try to establish a supply chain in geographic proximity while consciously taking into account local conditions in the business decisions. The textile and fashion industry, considered to be one of the world's largest consumer industries, acknowledges the need to improve its unsustainable ways (Eder-Hansen et al. 2017). The current industry is highly global, characterised by long, linear, fragmented, and non-transparent value chains which appear to be challenging to trace for consumers, NGOs, and the industry itself. However, there are some companies that pursue localism as an alternative to the current global modus operandi. By taking a closer look at four Norwegian fashion companies that try to source and manufacture locally, this chapter will explore (1) how localism can contribute to innovation in the business models and (2) what shared value can be generated by companies pursuing localism.

\section{Business Model Innovation for Sustainability}

Business models are explained as the logic of how companies do business (Osterwalder and Pigneur 2010; Teece 2010; Magretta 2002). These models describe how companies capture, create, and deliver value (e.g. Zott et al. 2011). While value creation is about the products and services a company offers, value delivery is the resources and activities needed to deliver the value creation, and the value capture relates to how to earn revenues. A business model can be seen as a reflection of 
a company's strategy (Casadesus-Masanell and Ricart 2010), and any component of the business model can be innovated to be in line with the strategy.

Business model innovation is increasingly considered central for building sustainable businesses (e.g. Boons and Lüdeke-Freund 2013; Evans et al. 2017). Sustainability-oriented innovation calls for more integrated thinking and the reconfiguration of several business elements such as capabilities, stakeholder relationships, knowledge management, leadership, and culture (Adams et al. 2016). Stubbs and Cocklin (2008: 123) argue that 'organizations adopting a sustainable business model develop internal structural and cultural capabilities to achieve firm-level sustainability and collaborate with key stakeholders to achieve sustainability for the system that the organization is part of.

Companies can innovate towards sustainability through small incremental steps or through more radical, disruptive transformations (Adams et al. 2016; Inigo et al. 2017). Roome and Louche (2016) have found that more sustainable business models are developed through interactions between individuals and groups inside and outside the companies. The changes entail: (i) building networks and collaborative practices for learning and action around a new vision; (ii) adopting new ideas and concepts from outside the company; and (iii) developing and implementing a structure within a reconfigured network (ibid.).

Creating a sustainable business model implies sustainability-oriented innovation which is explained as a dynamic and unfolding process (Adams et al. 2016). It is often more complex than conventional innovation because the company must take into account often contradictory demands of a broad range of stakeholders (Hall and Vredenburg 2003). It is worth noting that sustainability can be thought of as an ideal and that business models cannot be entirely sustainable (Lozano 2018).

Bocken and her colleagues (2014) have identified eight archetypes which describe groupings of mechanisms and solutions that can contribute to the development of business models for sustainability. In the organisationally oriented archetype Repurpose for society/environment which entails 'close integration between the firm and local communities and other stakeholder groups' (ibid.: 53), localisation is listed as an example under this archetype but is not presented further. In this chapter, 
the assumption is that localisation is related to localism and, therefore, a brief review of relevant literature follows.

\section{Localism}

At a general level, localism is a growing international trend focusing on re-establishing communities and protecting and rebuilding local economies (Hines 2013). It is about encouraging local livelihood through local production and consumption, and promotion of local identity. Localism can be considered a counter-movement to globalisation which has had economic, political, social, and ecological implications. Gray (2015: 57) argues that globalisation has 'uprooted activities and relationships from local origins and cultures' and calls it 'de-localisation'. Greater involvement from local communities has also been a highlighted path to promote sustainable development (ICLEI and IDRC 1996). Shrivastava and Kennelly argue that the 'grand project of sustainability will be given effect in places' (2013). To illustrate the prevalence of localism, initiatives such as Bioregional (Desai and Riddlestone 2002) and The Transition Town Movement have been expanding internationally.

Hess (2009) argues that there has been relatively little academic reflection about localism. Still, there has been related research across various disciplines and different sectors, but not all this literature uses the term localism. In the field of rural development, a 'new rural paradigm' is a counterforce to global competition logics in which a placebased focus embodies multifunctional agriculture and construction of identities linked to new rural goods and services (Horlings and Marsden 2014). The argumentation is that places have become increasingly 'place-less' due to reinforcing processes such as disconnection of producers, suppliers, and consumers and the goods and services (ibid.). There are also studies of local food systems (e.g. Marsden and Smith 2005; Jervell and Borgen 2004). Such local systems are claimed to be more sustainable since they have 'tight feedback loops' which reconnect consumers, producers, and ecological effects and stimulates improvements based on continuous feedback (Sundkvist et al. 2005). Another field, economic geography, highlights that innovation depends on proximity 
factors and that local knowledge and capabilities are important to build sustainable competitiveness (e.g. Maskell and Malmberg 1999).

Taking localism down at a company level, it is useful to look at the supply chain and operation management literature, as well as publications in the field of corporate social responsibility. The outsourcing trend of the last decades has led to global supply chains that often include many suppliers and, thereby, easily end up being non-transparent. These supply chains can cover shady social and environmental practices that leave the focal company busy with assuring control of its suppliers. Supply chain management scholars highlight that focal companies are increasingly held responsible for their supply chain's problems (Seuring and Müller 2008). The companies that have outsourced to lower-cost countries have started to take into account that lower costs are accompanied by ethical problems such as 'poorer labour conditions, less environmental protection, and lower attention to health and safety protection' (Crane and Matten 2016: 412). Thus, as corporate social responsibility scholars point out, outsourcing has been increasingly linked to problems outweighing the imposed cost savings (Carroll and Buchholtz 2012). As a result, the phenomena of reshoring (or backshoring, onshoring) is becoming increasingly evident in business practices (Fratocchi et al. 2014; Kinkel 2012) which refers to companies deciding to relocate their manufacturing to their home country.

Sustainable enterprising research has been criticised for being 'placeless', and that the relationship between companies and their sense of place (knowing and caring about a place) should not be overlooked when discussing the fostering of sustainable business behaviours (Shrivastava and Kennelly 2013; Guthey et al. 2014). The argument is that place-based enterprises 'offer a potentially important means of fostering ecological and social sustainability in local communities' (Shrivastava and Kennelly 2013: 83).

In the recent years, the number of publications on the topic of localism as an approach to sustainable fashion has been slowly growing (e.g. Fletcher 2013; Black 2008). When discussing environmental stewardship and sustainable sourcing in fashion, Quinn (2008) argues that if a company wants to incorporate sustainability in its business, it must start out with an understanding of what products are made of and how 
they are produced. To accomplish sustainable sourcing, thorough knowledge of the supply chain is required. This involves closer contact with the different supply partners and other relevant stakeholders (ibid.), and this is best achieved at a local scale. Generally, 'actors in each other's proximity have fewer conflicts, more trust towards each other, [...] and are thus more involved in knowledge transfer' (Dolfsma and Eijk 2016: 271).

There is scarce research about place-based companies and their innovation journey (Kibler et al. 2015), and localism in the fashion and textile industry seems more like a recommended path than something that is empirically investigated. Therefore, this chapter will contribute to more empirical insights on business model innovation for sustainability through localism.

\section{Method, Cases, and National Industry Context}

To empirically explore localism in business models, a list of relevant Norwegian fashion companies was compiled through purposeful sampling. The chosen sampling strategy deliberately selects cases since they can supply data about the phenomenon of interest (Yin 2009). Through dialogue with various fashion industry contacts, the companies were identified based on the criterion that they had parts of or their whole supply chain in Norway.

Sample and Research context: Of the four small companies selected for this study, two are start-ups and two are incumbents, and all have owners who are involved in daily operations. The four cases share a sustainability focus and the pursuit of localism-by trying to establish a local supply chain, both regarding sourcing local fibres and material (mainly wool) and locating manufacturing activities in Norway. Data were gathered through interviews of the companies' managers/founders/ owners at their offices and in their manufacturing facilities. These data were complemented with information derived from media coverage of the selected companies.

As place is naturally of importance in localism, one should also understand the cases' local context. After all, businesses do not develop independently; they are part of a community. For many years, Norway 
had a thriving textile industry based on wool, but this industry has undergone a decline since the 1950s (Espeli 1997). While the nation concentrated on building an oil-focused economy with high wages, many textile manufacturers were forced to outsource or shut down, leading to loss of jobs and industry knowledge (Hebrok et al. 2012). Consequently, the current industry situation can be characterised as incomplete from a supply chain perspective, and compared to other OECD-countries, the nation's textile and fashion industry has had little industrial importance for many decades (Espeli 1997).

\section{Findings-Localism's Contribution to Innovation in the Business Models}

With few local manufacturing partners available in Norway, two of the companies decided to invest in their own local factories. This implied innovation both in value creation and value delivery in their business models. Instead of doing design as the main business activity, they also included manufacturing in their business operations. The companies have experienced that in-house manufacturing stimulates innovation in the product design and manufacturing process (e.g. better utilisation of rest materials). To make the most out of the facilities, both expanded their value creation by offering different services at the factory. Company 1 offers manufacturing services to other fashion designers who want to produce locally and is also experimenting with additional services such as organising workshops for consumers in their factory after production hours. Company 2 has included a textile museum, a café, and a brand store in their facilities with the result of becoming an attraction for both tourists and other kinds of visitors.

Company 3 is a design studio which consciously seeks different local partners that can produce their designs. In their search, they came across a local shoe factory. Through dialogue, it became clear that the factory needed design expertise for the renewal of their collection. Therefore, the design studio expanded its value creation by offering design services and has experienced that this type of service 
is in demand by other local suppliers too. This innovation has led to increased income and altered revenue streams (part of the value capture). Also, it changes how the company collaborates with its partners, forming mutually beneficial partnerships with local suppliers.

As for sourcing local fibre, Company 4 changed its clothing collection to consist only of outerwear of local wool after they learned that Norwegian wool of the local sheep breeds is particularly suited for this type of wear. The company has been motivated to keep alive local craftsmanship and has had a close collaboration with local sheepfarmers, yarn makers, and weavers to develop the right kind of fabrics for their collections. Furthermore, the localism pursuit leads to innovation related to distribution, marketing, branding, and how the companies interact with their customers. Company 3 invites customers to events at their studio, and Company 1 organises workshops with consumers. These are multifunctional arenas where they can have a dialogue with customers (inform about their localism philosophy and get customer feedback that can be used to improve their collections), and they can sell their collections with higher earnings per product. Company 1 and Company 4, that have experience in production abroad, also find that a local supply chain allows shortened lead times, reduced costs related to customs and intermediaries, and ease of transport coordination. This has freed time and resources which they have invested in product improvements and the development of new business activities.

As presented earlier, all four companies want to source and manufacture in Norway, but in practice, they have encountered inhibiting industry conditions such as few remaining local manufacturing facilities in Norway and scarce supplies of local wool in the required quality. As a result, none of the companies has a completely local supply chain in Norway yet, but they are taking a step-by-step approach in their efforts to pursue localism. They seem to be encouraged by the challenge to revitalise the nation's textile and fashion industry and have a long-term perspective to get there. Meanwhile, they take a pragmatic approach, finding suppliers, and partners abroad, but look to the nearest possible shores such as the Baltics and other European countries, while they continuously search for opportunities and solutions that can give them a completely local supply chain (Table 11.1). 


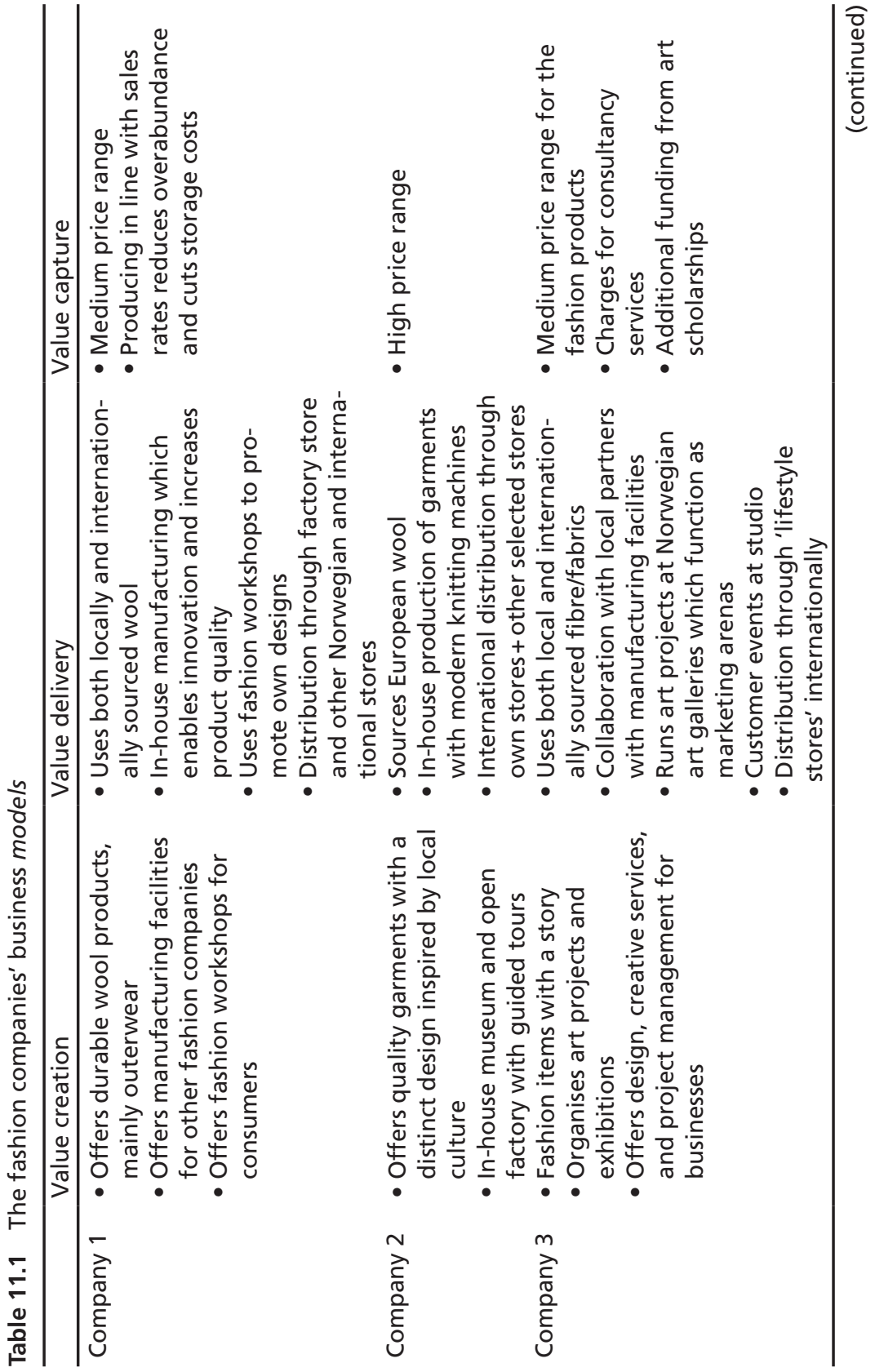




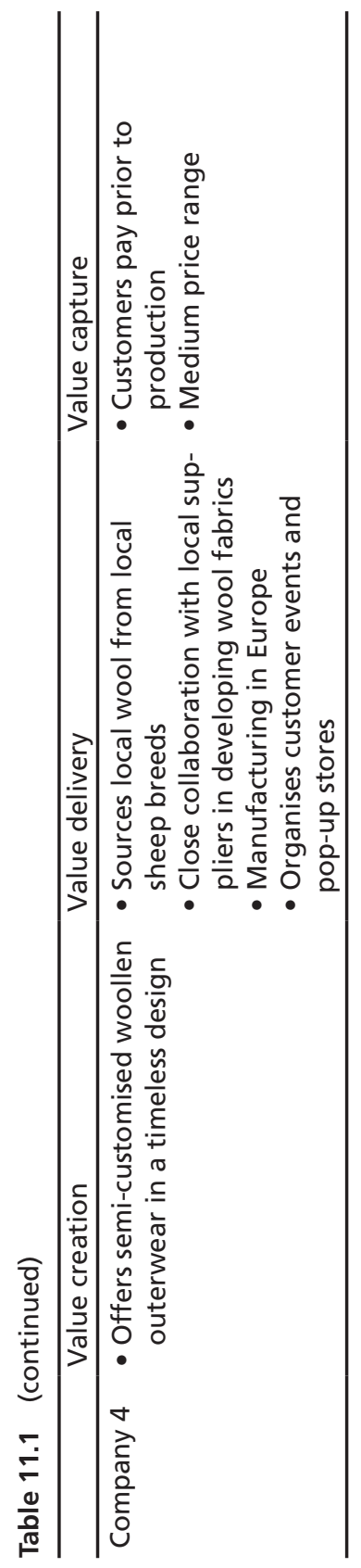




\section{Generating Shared Value Through Localism}

The explorative case studies indicate that localism leads to innovation in the business models of the selected companies, but what shared value can companies pursuing this strategy generate? All the cases argue that localism generates shared value since local supply chains enable responsive dialogue with the various stakeholders. The geographic proximity shortens the feedback loops, increases the chances of being aware of issues in the local community, and reduces transport emissions. Company 4, which started to produce outerwear, learned that most of the woollen clothes worn by Norwegians are made of imported wool, while Norwegian farmers get little value, and even discard some of the wool from local sheep breeds (Hebrok et al. 2012). Since the local wool has distinct qualities such as lustre, long durability, and little moisture absorption, they started, in collaboration with the local suppliers, to develop woollen fabrics to be used in their outerwear collection. By choosing to source locally, the company not only makes use of a pesticide-free, renewable, and traceable fibre but contributes to increased income for local farmers. This also works as an incentive for the farmers to sustain local sheep breeds (supporting biodiversity). Moreover, these sheep help to cultivate the overgrown outfields in Norway caused by a decline of grassing herds.

For the two companies with their own manufacturing facilities, the experience is that in-house production gives more control of the manufacturing process which leads to improved product quality and more efficient use of resources. The improved quality can lead to longer garment life. These companies also find that they can produce according to demand, instead of being forced to order large batches often required by manufacturers overseas. This lowers the risk of overproduction and flooding of clothes on the market. This is good for both business and the environment. Furthermore, Company 2, which made its facilities into a tourist attraction, not only brings visitors to the local community but also makes use of the facility as an educational arena. They offer guided tours informing about all the processes needed on the journey from fibre to garment. The idea is that access to the production facilities can create greater awareness of clothing production which may stimulate more sustainable consumer behaviour. 
The local factories create local manufacturing jobs and keep alive tacit industry knowledge. Company 4 also takes on fashion design apprentices to give them much-needed practical knowledge about clothing production. All the cases argue that their efforts to localise are motivated by their wish to help revitalise the national textile and fashion industry. They point out that a strengthened industry generates tax revenue which is shared value supporting the local welfare system. The overall effect is a contribution to building more resilient communities.

\section{Discussion-Localism as a Strategy to Build Business Models for Sustainability?}

The findings show that localism affects how the companies innovate different elements in their business models. The innovations happen evolutionarily through incremental changes in how the companies create, deliver, and capture value. This confirms sustainability-oriented innovation as a dynamic process (Adams et al. 2016) with experimentation and learning over time. The business model components are gradually changed, affected by enabling, and restricting factors in the local community. The companies are adapting 'the type of innovation they aim for to their particular context' (Szekely and Strebel 2013: 467). The cases evolve new business models through dialogue with a reconfigured network of local suppliers (Roome and Louche 2016). Although each separate alteration can be small, the sum of the adaptions the companies undertake can, over time, considerably change the business model designs. For example, Company 1 originally did only fashion design but, by investing in a manufacturing facility, also became a manufacturing company that started to experiment with workshops for consumers.

The companies explored in this chapter pursue a local supply chain, but they still distribute and sell some of their products on the international market. Offering mainly niche products with a medium to high price (to cover the costs of producing in a high-cost country), their customer segments are not large enough on a local scale. Therefore, one can argue that the cases are presently somewhere in between global 
and local, in other words, some variant of 'glocal'. Hypothetically, companies pursuing localism with a circular economy mindset could also sell to local customers who use, repair and recycle locally. Such 'local circularity' could stimulate business model innovations that, if up-scaled, can lead to radical changes in the current global linear system with a high degree of underutilisation of textiles and garments (Ellen MacArthur Foundation 2017).

To discuss localism and generation of shared value, the data reveal that localism leads to innovation in the business models that create shared value of both environmental and social character as well as the value of self-interest to the cases (Lüdeke-Freund et al. 2016). The findings indicate shared value such as reduced transport emissions, use of environmentally friendly wool from local sheep breeds, creation of local jobs, and revitalisation of an industry. As a best case, localism can even extend product life cycles, especially if the companies succeed with their efforts to increase consumer awareness, in other words, tackles some of the unsustainable issues in the current global fast fashion industry. The geographic proximity seems to enable a reconnection between resources, people, place, community, and environment that correlates with sustainability. This reconnection makes it easier to understand different forms of value exchanges which are essential when designing a sustainable business model (Bocken et al. 2015). Being part of the same community also means that the stakeholders are more likely to have common cultural and communicational denominators, which increase the chances of tight and effective feedback loops (Sundkvist et al. 2005). The cases experience that localism increases the chances that stakeholders are more receptive towards each other since they are all part of the same community.

Does this mean that one can link localism to sustainability? Not necessarily, since not all companies with a local supply chain have a sense of place or a sustainability focus like the cases in this study. Thomas and Cross (2007) highlight that there are exploitative place-based companies who are neither rooted to nor embedded in place. One factor that increases the likelihood of the sense of place is company size. Smaller companies tend to have employees, managers, and owners who live in the same geographic location and, therefore, have a closer connection 
to the community (Darnall et al. 2010). The cases in this study are all small companies where the managers, who also are the owners, seem connected to their local community. However, that does not mean that large or even multinational companies do not have a chance to pursue localism. Porter and Kramer (2011) have proposed that the strongest global corporations in the future will be the ones that have developed a mutually beneficial collaboration with local suppliers and grown deep roots in local communities.

There are also darker sides of localism that should be addressed. When companies that pursue localism reshore their production, they cause loss of jobs elsewhere in the world. For the developing countries, reshoring will have the same effects as outsourcing has had in the developed world, closed businesses and factories with the result of lost jobs and decreased tax incomes that negatively affect the local welfare systems (Carroll and Buchholtz 2012: 558). What makes outsourcing worse for the developing countries, is that the fashion and textile industry can be one of the few employment opportunities for the population, meaning that this is a stakeholder group that can experience negative effects of the localism strategy. One should not overlook the unintended consequences, calling for responsible considerations by the companies that pursue localism. Responsiveness to stakeholders in the local community is good, but one should not forget to take international stakeholders into account too.

\section{Conclusion}

This chapter has explored the innovation of business models for sustainability through localism. The closer look at four Norwegian fashion companies shows that localism appears to be a potential strategy to build business models for sustainability. The various innovations in the business models are mostly incremental, but in sum and over time, can represent a substantial change in the companies' business models.

The findings also reveal that localism can increase the chances of generating shared value of various forms, but it entails that the companies must have a sensitivity to place and be rooted and embedded in its local 
community. The proximity enables more dynamic and responsive relations which increase the chances for a more even distribution of value. However, it is important to emphasise that this study has the companies' point of view. It is left to other studies to verify all the stakeholders' perceptions of the value created. Localism does also have darker sides and should, therefore, be pursued in a responsible way. To conclude, localism appears as a potential sustainability strategy that should be explored further by scholars, policymakers, and business practitioners.

Acknowledgements This chapter builds on a study part of the research project Enhancing Wool Value Chains in Norway (244618) coordinated by Consumption Research Norway (SIFO), funded by the Research Council of Norway. The chapter was written and made open-access with financial support from NIFU. I want to thank my supervisors at Norwegian University of Life Sciences, my supportive colleagues at NIFU, the book editors, and anonymous reviewers for constructive feedback.

\section{References}

Adams, Richard, Sally Jeanrenaud, John Bessant, David Denyer, and Patrick Overy. 2016. "Sustainability-oriented innovation: A systematic review." International Journal of Management Reviews 18 (2): 180-205.

Black, Sandy. 2008. Eco-chic: The fashion paradox. London: Black Dog. Bocken, N. M. P., P. Rana, and S. W. Short. 2015. "Value mapping for sustainable business thinking." Journal of Industrial and Production Engineering 32 (1): 67-81.

Bocken, N. M. P., Samuel W. Short, Padmakshi Rana, and Steve Evans. 2014. "A literature and practice review to develop sustainable business model archetypes." Journal of Cleaner Production 65: 42-56.

Boons, Frank, and Florian Lüdeke-Freund. 2013. "Business models for sustainable innovation: State-of-the-art and steps towards a research agenda." Journal of Cleaner Production 45: 9-19.

Carroll, Archie B., and Ann K. Buchholtz. 2012. Business \& society: Ethics, sustainability, and stakeholder management. Boston, MA: Cengage Learning.

Casadesus-Masanell, Ramon, and Joan Enric Ricart. 2010. "From strategy to business models and onto tactics." Long Range Planning 43 (2-3): 195-215. 
Clinton, Lindsay, and Ryan Whisnant. 2014. Model behavior: 20 business model innovations for sustainability. Brooklyn, NY: SustainAbility.

Crane, Andrew, and Dirk Matten. 2016. Business ethics: Managing corporate citizenship and sustainability in the age of globalization. Oxford: Oxford University Press.

Darnall, Nicole, Irene Henriques, and Perry Sadorsky. 2010. "Adopting proactive environmental strategy: The influence of stakeholders and firm size." Journal of Management Studies 47 (6): 1072-94.

Desai, Pooran, and Sue Riddlestone. 2002. Bioregional solutions for living on one planet. Schumacher Briefings 8. London: Green books.

Dolfsma, Wilfred, and Rene Van der Eijk. 2016. "Distances in organizations: Innovation in an R\&D lab." British Journal of Management 27 (2): 271-86.

Eder-Hansen, Jonas, Caroline Chalmer, Sofia Tärneberg, Thomas Tochtermann, Javier F. Seara, Sebastian Sebastian Boger, Gabrielle Theelen, Sebastian Schwarz, Lise Kristensen, and Kristina Jäger. 2017. Pulse of the fashion industry. Copenhagen: Global Fashion Agenda \& The Boston Consulting Group.

Ellen MacArthur Foundation. 2017. A new textiles economy: Redesigning fashion's future.

Espeli, Harald. 1997. "Protectionism, lobbying and innovation: Perspectives on the development of the Norwegian textile industry, especially since 1940." Scandinavian Economic History Review 45 (3): 257-75.

Evans, Steve, Doroteya Vladimirova, Maria Holgado, Kirsten Van Fossen, Miying Yang, Elisabete A. Silva, and Claire Y. Barlow. 2017. "Business model innovation for sustainability: Towards a unified perspective for creation of sustainable business models." Business Strategy and the Environment 26 (5): 597-608.

Fletcher, Kate. 2013. Sustainable fashion and textiles: Design journeys. London and New York: Routledge.

Fratocchi, Luciano, Carmela Di Mauro, Paolo Barbieri, Guido Nassimbeni, and Andrea Zanoni. 2014. "When manufacturing moves back: Concepts and questions." Journal of Purchasing and Supply Management 20 (1): 54-59.

Gray, John. 2015. False dawn: The delusions of global capitalism. London: Granta Books.

Guthey, Greig Tor, Gail Whiteman, and Michael Elmes. 2014. "Place and sense of place: Implications for organizational studies of sustainability." Journal of Management Inquiry 23 (3): 254-65.

Hall, Anthony, and Harrie Vredenburg. 2003. "The challenge of sustainable development." MIT Sloan Management Review 45 (1): 61-68. 
Hebrok, Marie, Ingun Grimstad Klepp, Tone Skårdal Tobiasson, Kirsi Laitala, Marit Vestvik, and Madeline Buck. 2012. "Valuing Norwegian Wool." National Institute for Consumer Research (SIFO). Professional report 5-2012.

Hess, David J. 2009. Localist movements in a global economy: Sustainability, justice, and urban development in the United States. Cambridge, MA: MIT Press.

Hines, Colin. 2013. Localization: A global manifesto. London: Routledge.

Horlings, Lummina G., and Terry K. Marsden. 2014. "Exploring the 'New Rural Paradigm' in Europe: Eco-economic strategies as a counterforce to the global competitiveness agenda." European Urban and Regional Studies 21 (1): 4-20.

International Council for Local Environmental Initiatives (ICLEI) and The International Development Research Centre (IDRC). 1996. The Local Agenda 21 Planning Guide. Toronto: The International Development Research Centre (IDRC).

Inigo, Edurne A., Laura Albareda, and Paavo Ritala. 2017. "Business model innovation for sustainability: Exploring evolutionary and radical approaches through dynamic capabilities." Industry and Innovation 24 (5): 515-42.

Jervell, Anne Moxnes, and Svein Ole Borgen. 2004. "New marketing channels for food quality products in Norway." Food Economics-Acta Agriculturae Scandinavica, Section C 1 (2): 108-18.

Kibler, Ewald, Matthias Fink, Richard Lang, and Pablo Muñoz. 2015. "Place attachment and social legitimacy: Revisiting the sustainable entrepreneurship journey." Journal of Business Venturing Insights 3: 24-29.

Kinkel, Steffen. 2012. "Trends in production relocation and backshoring activities: Changing patterns in the course of the global economic crisis." International Journal of Operations \& Production Management 32 (6): 696-720.

Lozano, Rodrigo. 2018. "Sustainable business models: Providing a more holistic perspective." Business Strategy and the Environment. https://doi. org/10.1002/bse.2059.

Lüdeke-Freund, Florian, Lorenzo Massa, Nancy Bocken, Alan Brent, and Josephine Musango. 2016. "Business models for shared value." Cape Town: Network for Business Sustainability South Africa.

Magretta, Joan. 2002. "Why business models matter." Harvard Business Review 80 (5): 86-92. 
Marsden, Terry, and Everard Smith. 2005. "Ecological entrepreneurship: Sustainable development in local communities through quality food production and local branding." Geoforum 36 (4): 440-51.

Maskell, Peter, and Anders Malmberg. 1999. "Localised learning and industrial competitiveness." Cambridge Journal of Economics 23 (2): 167-85.

Osterwalder, Alexander, and Yves Pigneur. 2010. Business model generation: A handbook for visionaries, game changers, and challengers. Hoboken, NJ: Wiley.

Porter, Michael E., and Mark R. Kramer. 2011. "The big idea: Creating shared value." Harvard Business Review 89 (1): 2.

Quinn, S. 2008. 'Environmental stewardship and sustainable sourcing.' In Sustainable fashion: Why now, edited by J. Hethorn \& C. Ulasewicz, 358-84. New York: Fairchild Books.

Roome, Nigel, and Céline Louche. 2016. "Journeying toward business models for sustainability: A conceptual model found inside the black box of organisational transformation." Organization \& Environment 29 (1): 11-35.

Seuring, Stefan, and Martin Müller. 2008. "From a literature review to a conceptual framework for sustainable supply chain management." Journal of Cleaner Production 16 (15): 1699-710.

Shrivastava, Paul, and James J. Kennelly. 2013. "Sustainability and place-based enterprise." Organization \& Environment 26 (1): 83-101.

Stubbs, Wendy, and Chris Cocklin. 2008. "Conceptualizing a 'sustainability business model'." Organization \& Environment 21 (2): 103-27.

Sundkvist, Åsa, Rebecka Milestad, and AnnMari Jansson. 2005. "On the importance of tightening feedback loops for sustainable development of food systems." Food Policy 30 (2): 224-39.

Szekely, Francisco, and Heidi Strebel. 2013. "Incremental, radical and game-changing: Strategic innovation for sustainability." Corporate Governance 13 (5): 467-81.

Teece, David J. 2010. "Business models, business strategy and innovation." Long Range Planning 43 (2-3): 172-94.

Thomas, David F., and Jennifer E. Cross. 2007. "Organizations as place builders." Journal of Behavioral and Applied Management 9 (1): 33.

Yin, Robert K. 2009. Case study research and applications: Design and methods. Los Angeles: Sage. 
Zott, Christoph, and Raphael Amit. 2008. "The fit between product market strategy and business model: Implications for firm performance." Strategic Management Journal 29 (1): 1-26.

Zott, Christoph, Raphael Amit, and Lorenzo Massa. 2011. "The business model: Recent developments and future research." Journal of Management 37 (4): 1019-42.

Open Access This chapter is licensed under the terms of the Creative Commons Attribution 4.0 International License (http://creativecommons. org/licenses/by/4.0/), which permits use, sharing, adaptation, distribution and reproduction in any medium or format, as long as you give appropriate credit to the original author(s) and the source, provide a link to the Creative Commons licence and indicate if changes were made.

The images or other third party material in this chapter are included in the chapter's Creative Commons licence, unless indicated otherwise in a credit line to the material. If material is not included in the chapter's Creative Commons licence and your intended use is not permitted by statutory regulation or exceeds the permitted use, you will need to obtain permission directly from the copyright holder.

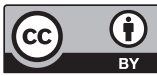

